\title{
Lower Psychological Distress Levels among Returnees Compared with Evacuees after the Fukushima Nuclear Accident
}

\author{
Michio Murakami, ${ }^{1}$ Yoshitake Takebayashi ${ }^{1}$ and Masaharu Tsubokura ${ }^{1,2}$ \\ ${ }^{1}$ Fukushima Medical University School of Medicine, Fukushima, Fukushima, Japan \\ ${ }^{2}$ Minamisoma Municipal General Hospital, Minamisoma, Fukushima, Japan
}

\begin{abstract}
Psychological distress has become a serious health risk after the Fukushima nuclear accident. Although, following the lifting of evacuation orders, the affected people have started returning home, their current status of psychological distress has not been reported yet. Here, we report the levels of psychological distress in both returnees and evacuees by using a K6 indicator. In January 2018, questionnaires were randomly distributed among 2,000 people, aged 20 to 79 years old, who were registered on the Basic Resident Register in the evacuation order areas of nine municipalities where residents have now started returning home. The total number of participants was 625 . The returnees showed a significantly better psychological distress status than the evacuees. Multivariate-adjusted odds ratios $(95 \%$ confidence intervals) among the returnees (reference $=$ evacuees), estimated from a logistic analysis by using age, sex, and annual income as covariates, were $0.525(0.325-0.846)$ for $K 6 \geq 10$ and $0.444(0.216-0.911)$ for $K 6 \geq 13$. The prevalence of $K 6 \geq 10$ in the returnees when adjusted by the age and sex distribution of the whole of Japan was $16.2 \%$, higher than the value $(10.3 \%)$ at 20 to 79 years old in the whole of Japan. Psychological distress among the evacuees is an urgent problem to be resolved, and social support is still necessary for the returnees. Long term follow-up of returnees, investigations of causality between return and psychological distress and its governing factors in each of the evacuee and returnee groups are required for the implementation of effective countermeasures.
\end{abstract}

Keywords: evacuation; Fukushima disaster; Kessler 6-item scale; mental health; returning home Tohoku J. Exp. Med., 2019 January, 247 (1), 13-17. C 2019 Tohoku University Medical Press

\section{Introduction}

The Great East Japan Earthquake and the subsequent Fukushima nuclear accident in 2011 (hereinafter, 2011 disaster) posed multiple health risks. In particular, psychological distress has become a serious health risk after the 2011 disaster (United Nations Scientific Committee on the Effects of Atomic Radiation 2014; Murakami et al. 2018b), as had also been found after the Chernobyl accident (World Health Organization 2006). Since psychological distress is associated with a decline in well-being (Murakami et al. 2018a), and may also cause an additional mortality risk including suicide (Pratt 2009), the improvement of psychological distress levels has become an urgent requirement after the 2011 disaster.

A previous study implied that psychological distress levels among evacuees living outside the Fukushima prefecture was higher than that among those living inside the Fukushima prefecture (Oe et al. 2016). Furthermore, a previous study regarding a natural disaster showed that returnees have lower psychological distress levels than evacuees (Fussell and Lowe 2014). Although, following the lifting of evacuation orders, the affected people have started returning home, their current status of psychological distress after the 2011 disaster has not been reported yet. The understanding of the current status of psychological distress among returnees and evacuees is expected to facilitate the development and implementation of effective countermeasures.

Here, we report the levels of psychological distress in both returnees and evacuees by using a K6 indicator. This is the first study to investigate the association between returned condition and psychological distress among the people affected by the 2011 disaster.

\section{Methods}

Ethics approval was granted by the ethics committee of the Fukushima Medical University (authorization number: General 29199). Psychological distress status among evacuees has been longitudinally measured under the Fukushima Health Management Survey (Oe et al. 2016) on the Kessler 6-item scale (K6), which poses six brief questions about non-specific psychological distress during

Received November 5, 2018; revised and accepted December 20, 2018. Published online January 11, 2019; doi: 10.1620/tjem.247.13. Correspondence: Michio Murakami, Fukushima Medical University School of Medicine, 1 Hikarigaoka, Fukushima, Fukushima 9601295, Japan. e-mail: michio@fmu.ac.jp 
the past 30 days (Kessler et al. 2003). The subjects included people aged between people 20 to 79 years old and registered on the Basic Resident Register in the evacuation order areas of nine municipalities where residents have now started returning home: Tamura, Minamisoma, Kawamata, Hirono, Naraha, Tomioka, Kawauchi, Katsurao, and Iitate. We first determined the number of subjects in each municipality, in accordance with the distribution of the people who had been forced to evacuate (United Nations Scientific Committee on the Effects of Atomic Radiation 2014), and we then randomly chose 2,000 subjects. In January 2018, questionnaires were distributed to the selected subjects.

From 2,000 questionnaires, of which 167 were returned as "address unknown," we received 826 responses (response rate = $45.1 \%$ ). Responses were excluded if there was a discrepancy of sex or age ( $>1$ year) between the response and the register information, if participants were not evacuated after the accident, or if there were missing data in the K6 or evacuated/returned condition. The total number of final participants was 625 .

Psychological distress levels were assessed on the K6 (Kessler et al. 2003). The K6 consists of six brief questions ranging from 0 (never) to 4 (all the time) as follows: 'During the past $30 \mathrm{~d}$, about how often did you feel nervous/hopeless/restless or fidgety/so depressed that nothing could cheer you up/that everything was an effort/worthless?' The total score ranges from 0 to 24 . Since Japanese studies often use a cutoff of $\mathrm{K} 6 \geq 10$ as an indicator of mood/anxiety disorders or $\mathrm{K} 6 \geq 13$ as an indicator of serious mental illness (Furukawa et al. 2008; Koyama et al. 2014; Oe et al. 2016; Sone et al. 2016), we used both cutoffs in this study. Other questionnaire items focused on evacuated/returned condition and socio-demographic factors (i.e., age, sex, history of mental illness, and annual income). The history of mental illness and income status were reported to assess their association with psychological distress levels after the 2011 disaster (Suzuki et al. 2015).

We first used chi-squared tests to assess the associations between socio-demographic factors and evacuated/returned condition, and that between these variables and psychological distress levels. We then conducted a binominal logistic analysis to investigate the associations between evacuated/returned condition (explanatory variable) and the psychological distress levels (objective variable). In addition to age and sex, annual income was added as a covariate, because it had significant associations with both evacuated/returned condition and psychological distress levels in the chi-squared tests. Dummy variables were created for evacuated/returned condition, age, sex, and annual income. Variance inflation factors (VIF) were $\leq 1.431$, and the impact of multicollinearity was found to be small. All analyses were performed using the IBM SPSS Statistics 24 software.

\section{Results and Discussion}

All the socio-demographic factors of the returnees and evacuees were compared (Table 1). There were significant differences in age and annual income distributions between the two groups $(P<0.05)$ : older or lower-income people were more likely to have returned home. However, there were no significant differences in sex and history of mental illness between the two groups $(P>0.10)$.

Arithmetic mean \pm standard deviation of $\mathrm{K} 6$ in the subjects was $6.25 \pm 4.81$. The prevalence of $K 6 \geq 10$ and K6 $\geq 13$ was $22.9 \%$ and $9.9 \%$, respectively. The returnees showed a significantly better psychological distress status than the evacuees (Fig. 1): $P<0.05$ for K6 $\geq 10 ; P=0.06$ for $\mathrm{K} 6 \geq 13$. Table 2 shows associations between evacuated/retuned condition or socio-demographic factors and psychological distress levels. For both cutoffs, the history of mental illness and annual incomes were significantly associated with psychological distress levels $(P$ $=0.09$ for annual income and $\mathrm{K} 6 \geq 13 ; P<0.01$ for other

Table 1. Basic characteristics of evacuees and returnees.

\begin{tabular}{|c|c|c|c|c|c|}
\hline & & $\begin{array}{l}\text { Total } \\
\mathrm{N}(\%)\end{array}$ & $\begin{array}{c}\text { Evacuees } \\
\mathrm{N}(\%)\end{array}$ & $\begin{array}{l}\text { Returnees } \\
\mathrm{N}(\%)\end{array}$ & $P^{\mathrm{a}}$ \\
\hline \multirow[t]{6}{*}{ Age } & $20 \mathrm{~s}$ & $34(5.4 \%)$ & $30(6.8 \%)$ & $4(2.2 \%)$ & $<0.001$ \\
\hline & $30 \mathrm{~s}$ & $33(5.3 \%)$ & $22(5.0 \%)$ & $11(5.9 \%)$ & \\
\hline & $40 \mathrm{~s}$ & $75(12.0 \%)$ & $63(14.3 \%)$ & $12(6.5 \%)$ & \\
\hline & $50 \mathrm{~s}$ & $152(24.3 \%)$ & $114(25.9 \%)$ & $38(20.5 \%)$ & \\
\hline & $60 \mathrm{~s}$ & $220(35.2 \%)$ & $146(33.2 \%)$ & $74(40.0 \%)$ & \\
\hline & $\geq 70$ years old & $111(17.8 \%)$ & $65(14.8 \%)$ & $46(24.9 \%)$ & \\
\hline \multirow[t]{2}{*}{ Sex } & Men & $313(50.1 \%)$ & $221(50.2 \%)$ & $92(49.7 \%)$ & $>0.10$ \\
\hline & Women & $312(49.9 \%)$ & $219(49.8 \%)$ & $93(50.3 \%)$ & \\
\hline \multirow[t]{2}{*}{ History of mental illness } & Absence & $578(92.5 \%)$ & $406(92.3 \%)$ & $172(93.0 \%)$ & $>0.10$ \\
\hline & Presence & $47(7.5 \%)$ & $34(7.7 \%)$ & $13(7.0 \%)$ & \\
\hline \multirow[t]{4}{*}{ Annual income } & $<3$ million Yen & $291(47.8 \%)$ & $201(46.6 \%)$ & $90(50.6 \%)$ & 0.03 \\
\hline & 3-6 million Yen & $165(27.1 \%)$ & $108(25.1 \%)$ & $57(32.0 \%)$ & \\
\hline & $\geq 6$ million Yen & $102(16.7 \%)$ & $81(18.8 \%)$ & $21(11.8 \%)$ & \\
\hline & $\begin{array}{l}\text { Do not want to } \\
\text { answer }\end{array}$ & $51(8.4 \%)$ & $41(9.5 \%)$ & $10(5.6 \%)$ & \\
\hline
\end{tabular}

${ }^{\mathrm{a} C h i}$-squared test. 


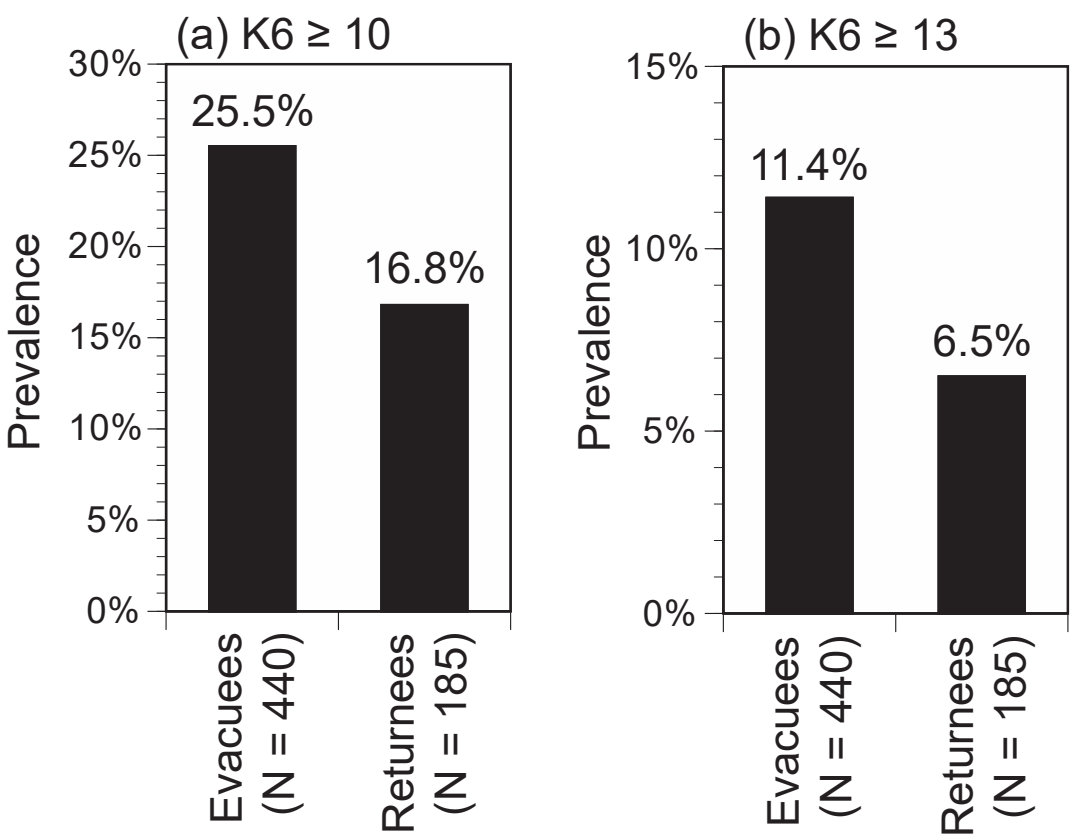

Fig. 1. Psychological distress levels in evacuees and returnees.

(a) K6 $\geq 10$, (b) K6 $\geq 13$. Chi-squared test: $P=0.02$ (K6 $\geq 10), P=0.06(\mathrm{~K} 6 \geq 13)$.

Table 2. Associations between socio-demographic factors and psychological distress.

\begin{tabular}{|c|c|c|c|c|c|c|c|}
\hline & & $\mathrm{K} 6<10$ & $K 6 \geq 10$ & $P a$ & $K 6<13$ & $K 6 \geq 13$ & $P_{a}$ \\
\hline \multirow[t]{6}{*}{ Age } & $20 s$ & $23(67.6 \%)$ & $11(32.4 \%)$ & $>0.10$ & $30(88.2 \%)$ & $4(11.8 \%)$ & $>0.10$ \\
\hline & $30 \mathrm{~s}$ & $20(60.6 \%)$ & $13(39.4 \%)$ & & $28(84.8 \%)$ & $5(15.2 \%)$ & \\
\hline & $40 \mathrm{~s}$ & $58(77.3 \%)$ & $17(22.7 \%)$ & & $67(89.3 \%)$ & $8(10.7 \%)$ & \\
\hline & $50 s$ & $123(80.9 \%)$ & $29(19.1 \%)$ & & $141(92.8 \%)$ & $11(7.2 \%)$ & \\
\hline & $60 s$ & $173(78.6 \%)$ & $47(21.4 \%)$ & & $197(89.5 \%)$ & $23(10.5 \%)$ & \\
\hline & $\geq 70$ years old & $85(76.6 \%)$ & $26(23.4 \%)$ & & $100(90.1 \%)$ & $11(9.9 \%)$ & \\
\hline \multirow[t]{2}{*}{ Sex } & Men & $242(77.3 \%)$ & $71(22.7 \%)$ & $>0.10$ & $281(89.8 \%)$ & $32(10.2 \%)$ & $>0.10$ \\
\hline & Women & $240(76.9 \%)$ & $72(23.1 \%)$ & & $282(90.4 \%)$ & $30(9.6 \%)$ & \\
\hline \multirow[t]{2}{*}{ History of mental illness } & Absence & $460(79.6 \%)$ & $118(20.4 \%)$ & $<0.001$ & $531(91.9 \%)$ & $47(8.1 \%)$ & $<0.001$ \\
\hline & Presence & $22(46.8 \%)$ & $25(53.2 \%)$ & & $32(68.1 \%)$ & $15(31.9 \%)$ & \\
\hline \multirow[t]{4}{*}{ Annual income } & $<3$ million Yen & $217(74.6 \%)$ & $74(25.4 \%)$ & 0.007 & $255(87.6 \%)$ & $36(12.4 \%)$ & 0.09 \\
\hline & 3-6 million Yen & $132(80.0 \%)$ & $33(20.0 \%)$ & & $151(91.5 \%)$ & $14(8.5 \%)$ & \\
\hline & $\geq 6$ million Yen & $90(88.2 \%)$ & $12(11.8 \%)$ & & $98(96.1 \%)$ & $4(3.9 \%)$ & \\
\hline & $\begin{array}{l}\text { Do not want to } \\
\text { answer }\end{array}$ & $34(66.7 \%)$ & 17 (33.3\%) & & $46(90.2 \%)$ & $5(9.8 \%)$ & \\
\hline
\end{tabular}

${ }^{\mathrm{a} C h i-s q u a r e d ~ t e s t . ~}$

associations). However, insignificant associations were observed for age and sex $(P>0.10)$.

Multivariate-adjusted odds ratios $(95 \%$ confidence intervals) among the returnees (reference $=$ evacuees), estimated from a logistic analysis by using age, sex, and annual income as covariates, were $0.525(0.325-0.846)$ for $\mathrm{K} 6 \geq 10$ and $0.444(0.216-0.911)$ for $\mathrm{K} 6 \geq 13$, exhibiting that the returnees had lower levels of serious psychological distress than the evacuees, even after adjusting the sociodemographic factors (Table 3). This finding was consistent in part with the previous studies regarding the effects of natural disasters (Bland et al. 1997; Fussell and Lowe 2014). In comparison to the long period of life they have spent as evacuees, life in a familiar home might improve 
Table 3. Multivariate-adjusted odds ratios and 95\% CIs for psychological distress.

\begin{tabular}{|c|c|c|c|}
\hline & & $\mathrm{K} 6 \geq 10$ & $K 6 \geq 13$ \\
\hline & VIF & ORs $(95 \% \mathrm{Cl})$ & ORs $(95 \% \mathrm{Cl})$ \\
\hline \multicolumn{4}{|c|}{ Evacuated or returned condition (ref: evacuees) } \\
\hline Returnees & 1.046 & $0.525(0.325-0.846)$ & $0.444(0.216-0.911)$ \\
\hline \multicolumn{4}{|l|}{ Age (ref: 60s) } \\
\hline $20 \mathrm{~s}$ & 1.143 & $1.623(0.712-3.699)$ & $1.121(0.348-3.612)$ \\
\hline $30 \mathrm{~s}$ & 1.128 & $2.568(1.147-5.753)$ & $1.835(0.616-5.468)$ \\
\hline $40 \mathrm{~s}$ & 1.306 & $1.353(0.688-2.660)$ & $1.344(0.539-3.350)$ \\
\hline $50 \mathrm{~s}$ & 1.431 & $1.140(0.654-1.989)$ & $0.935(0.421-2.079)$ \\
\hline$\geq 70$ years old & 1.250 & $1.010(0.563-1.813)$ & $0.938(0.421-2.090)$ \\
\hline \multicolumn{4}{|l|}{ Sex (ref: men) } \\
\hline Women & 1.050 & $0.887(0.592-1.327)$ & $0.923(0.527-1.617)$ \\
\hline \multicolumn{4}{|c|}{ Annual income (ref: $<3$ million Yen) } \\
\hline 3-6 million Yen & 1.255 & $0.708(0.432-1.162)$ & $0.640(0.321-1.276)$ \\
\hline$\geq 6$ million Yen & 1.335 & $0.339(0.168-0.684)$ & $0.258(0.085-0.784)$ \\
\hline Do not want to answer & 1.146 & $1.199(0.611-2.353)$ & $0.655(0.234-1.831)$ \\
\hline
\end{tabular}

the psychological status of the affected people. In this regard, however, there might be a potential opposite causality: people with better psychological status were more likely to have returned home.

The prevalence of $\mathrm{K} 6 \geq 10$ in the returnees, when adjusted by the age and sex distribution of the whole of Japan, was $16.2 \%$; this was higher than the value $(10.3 \%)$ for individuals aged between 20 to 79 years old in the whole of Japan (Ministry of Health, Labour and Welfare, 2017). This result highlighted the importance of the need for countermeasures for both returnees and evacuees. Irrespective of the direction of causality, it is a fact that the returnees had a lower level of psychological distress than the evacuees; however, it should be noted that the psychological status of the returnees were worse than the national average. Psychological distress among the evacuees is an urgent problem that needs to be resolved, and social support still remains an urgent requirement for the returnees. Since the returnees were dominated by the older and lower-income people, some specific strategies for the elderly, in addition to providing employment assistance, may be promising.

This study had some limitations. First, since the response rate was not so high $(45.1 \%)$, there might be a potential sampling bias. Second, as this was a cross sectional study, any causal relationships between returned condition and psychological distress could not be inferred. Third, there might be other potential factors governing both psychological distress and returning home. Fourth, we did not investigate the temporal changes in psychological status of the affected people after they had returned home. Our study showed that psychological distress levels among returnees was lower than that among evacuees, but higher than that among the whole of Japan, indicating that there was still a high-risk group of psychological distressed individuals among the returnees. Changes in the sociodemographic profiles of the returnees post-disaster, and in the living and working environment of some residents who are new to the municipalities may temporarily affect their psychological status. Long term follow-up of returnees is required along with investigations of causality between returned condition and psychological distress and its governing factors in both the evacuee and returnee groups to ensure development and implementation of effective countermeasures.

Despite the limitations stated above, this study has provided an advanced understanding of psychological distress levels among returnees after a nuclear disaster.

\section{Acknowledgments}

This paper was supported by JSPS KAKENHI grant number JP17K20069.

\section{Conflict of Interest}

The authors declare no conflict of interest.

\section{References}

Bland, S.H., O’Leary, E.S., Farinaro, E., Jossa, F., Krogh, V., Violanti, J.M. \& Trevisan, M. (1997) Social network disturbances and psychological distress following earthquake evacuation. J. Nerv. Ment. Dis., 185, 188-194.

Furukawa, T.A., Kawakami, N., Saitoh, M., Ono, Y., Nakane, Y., Nakamura, Y., Tachimori, H., Iwata, N., Uda, H., Nakane, H., Watanabe, M., Naganuma, Y., Hata, Y., Kobayashi, M., Miyake, Y., et al. (2008) The performance of the Japanese version of the K6 and K10 in the World Mental Health Survey Japan. Int. J. Methods Psychiatr. Res., 17, 152-158.

Fussell, E. \& Lowe, S.R. (2014) The impact of housing displacement on the mental health of low-income parents after Hurricane Katrina. Soc. Sci. Med., 113, 137-144. 
Kessler, R.C., Barker, P.R., Colpe, L.J., Epstein, J.F., Gfroerer, J.C., Hiripi, E., Howes, M.J., Normand, S.L., Manderscheid, R.W., Walters, E.E. \& Zaslavsky, A.M. (2003) Screening for serious mental illness in the general population. Arch. Gen. Psychiatry, 60, 184-189.

Koyama, S., Aida, J., Kawachi, I., Kondo, N., Subramanian, S.V., Ito, K., Kobashi, G., Masuno, K., Kondo, K. \& Osaka, K. (2014) Social support improves mental health among the victims relocated to temporary housing following the Great East Japan Earthquake and Tsunami. Tohoku J. Exp. Med., 234, 241-247.

Ministry of Health, Labour and Welfare (2017) Comprehensive survey of living conditions in 2016 Secondary Comprehensive survey of living conditions in 2016.

https://www.mhlw.go.jp/toukei/saikin/hw/k-tyosa/k-tyosa16/ dl/16.pdf

[Accessed: 28 October, 2018] (in Japanese).

Murakami, M., Hirosaki, M., Suzuki, Y., Maeda, M., Yabe, H., Yasumura, S. \& Ohira, T. (2018a) Reduction of radiationrelated anxiety promoted wellbeing after the 2011 disaster: 'Fukushima Health Management Survey.' J. Radiol. Prot., 38, 1428-1440.

Murakami, M., Tsubokura, M., Ono, K. \& Maeda, M. (2018b) New "loss of happy life expectancy" indicator and its use in risk comparison after Fukushima disaster. Sci. Total Environ., 615, 1527-1534.

Oe, M., Fujii, S., Maeda, M., Nagai, M., Harigane, M., Miura, I., Yabe, H., Ohira, T., Takahashi, H., Suzuki, Y., Yasumura, S. \& Abe, M. (2016) Three-year trend survey of psychological distress, post-traumatic stress, and problem drinking among residents in the evacuation zone after the Fukushima Daiichi Nuclear Power Plant accident [The Fukushima Health Management Survey]. Psychiatry Clin. Neurosci., 70, 245-252.

Pratt, L.A. (2009) Serious psychological distress, as measured by the K6, and mortality. Ann. Epidemiol., 19, 202-209.

Sone, T., Nakaya, N., Sugawara, Y., Tomata, Y., Watanabe, T. \& Tsuji, I. (2016) Longitudinal association between timevarying social isolation and psychological distress after the Great East Japan Earthquake. Soc. Sci. Med., 152, 96-101.

Suzuki, Y., Yabe, H., Yasumura, S., Ohira, T., Niwa, S., Ohtsuru, A., Mashiko, H., Maeda, M. \& Abe, M.; Mental Health Group of the Fukushima health management survey (2015) Psychological distress and the perception of radiation risks: the Fukushima health management survey. Bull. World Health Organ., 93, 598-605.

United Nations Scientific Committee on the Effects of Atomic Radiation (2014) Sources, effects and risks of ionizing radiation. UNSCEAR 2013 Reports to the General Assembly with Scientific Annexes. United Nations, New York. http://www.unscear.org/unscear/en/publications/2013_1.html [Accessed: December 26, 2018].

World Health Organization (2006) Health Effects of the Chernobyl accident and Special Health Care Programmes: Report of the UN Chernobyl Forum Expert Group "Health". http://apps.who.int/iris/bitstream/10665/43447/1/924159417 9_eng.pdf

[Äccessed: December 26, 2018]. 